\title{
A pesquisa qualitativa e o trabalho das enfermeiras obstétricas
}

\author{
Tatiane de Souza Mançú́, Milena Bastos Brito², Mônica Ramos Daltro³ \\ 1Autora para correspondência. Escola Bahiana de Medicina e Saúde Pública. Salvador, Bahia, Brasil. tatianemancu.pos@bahiana.edu.br \\ 2Escola Bahiana de Medicina e Saúde Pública. Salvador, Bahia, Brasil. milenabrito@bahiana.edu.br \\ 3Escola Bahiana de Medicina e Saúde Pública. Salvador, Bahia, Brasil. monicadaltro@bahiana.edu.br
}

A enfermeira obstétrica lida com o nascimento que traz em si diversos significados. Em uma perspectiva científica, mediante a abordagem quantitativa, questões subjetivas que permeiam o ciclo gravídico-puerperal não seriam avaliadas. Isso porque, trata-se de um fenômeno complexo, ou melhor, multidimensional que envolve significados, emoções, percepções, mas também crenças, perspectivas culturais e religiosas, tanto das usuárias quanto das equipes de saúde.

Nesse cenário, a enfermeira obstétrica que atua na prestação de cuidado à mulher, família e bebê, tem o desafio de lidar com a avalanche de significações existentes no ciclo gravídico-puerperal da mulher, que envolve a chegada do recém-nascido ao mundo.

A assistência à saúde no período gravídico puerperal é objeto de muitas questões de pesquisa. Nesse universo de possibilidades investigativas são mais comuns estudos que envolvem: 0 conhecimento sobre o binômio mãe-feto ou recém-nascido e suas vivências em cada momento do parto natural; a relação entre o parto cesariano de escolha ou de urgência com o bem estar psicoemocional desta nova mãe, ou ainda; o conhecimento das distintas modalidades de sofrimento implicadas em processos gestacionais normais ou atravessados por processos patológicos.

São também destacados estudos referentes aos sentimentos e construções cognitivas da sociedade sobre o parto natural/normal, assim como, sobre as significações atribuídas às dores do parto ou ainda as relações com o sistema de saúde e seus modos de operar o processo de cuidado. Outro ponto polêmico, que frequentemente demanda novas pesquisas está relacionado a falta de conhecimento/informações/orientações das gestantes, a fragilidade comunicacional com as equipes de saúde durante $\circ$ pré-natal e a violência obstétrica.

Conhecer as demandas desse grupo populacional por meio de pesquisas qualitativas é de extrema relevância para a assistência prestada. Tão importante quanto as pesquisas quantitativas, a pesquisa qualitativa tem a riqueza de resultados que beneficiam a sociedade e a comunidade cientifica. 
As limitações da metodologia clássica (quantitativa) de investigação desencadeavam uma visão parcial do processo dinâmico das experiências vividas num contexto histórico e cultural. As dificuldades das enfermeiras em reunir partes fragmentadas de dados coletados por meio de métodos quantitativos, levou as pesquisadoras a examinar a importância de métodos qualitativos ${ }^{1}$.

Para responder questões de pesquisas levantadas pelas enfermeiras obstétricas, diversos métodos qualitativos com rigor cientifico podem ser utilizados, a fim de gerar novas informações e conhecimentos. Mas, são poucos os métodos científicos utilizados pelas enfermeiras. As enfermeiras obstétricas, dentre as abordagens qualitativas, comumente utilizam os estudos de caso, os relatos de experiência, a análise documental e os estudos etnográficos.

A abordagem qualitativa da pesquisa cientifica amplia as possibilidades de conhecimento no campo da enfermagem. Muitos estudos conduzidos por enfermeiras, ao longo das últimas décadas analisaram sentimentos, como empatia, simpatia, sofrimento, solidariedade e liberdade, evidenciando o compromisso da profissão com os processos de humanização e cuidado que envolvem a prática profissional e científica ${ }^{2}$.

O paradigma das ciências humanas adequa-se bem à pesquisa em enfermagem, pois possibilita o uso de metodologias que tomam a experiência humana, em sua dimensão complexa, como fenômeno a ser compreendido ${ }^{3}$. Para alcançar esse objetivo, vale-se de uma grande variedade de desenhos de estudos: etnografias, análises narrativas, pesquisa ação, análises documentais e históricas e relatos de experiências. $O$ uso desse modelo metodológico é um esforço por parte das pesquisadoras de diversas áreas e também de pesquisadoras enfermeiras em compreender a significação do seu trabalho e não somente em contemplar sua vivencia ${ }^{4}$.

Uma pesquisa bibliográfica realizada para identificar temas emergentes nas pesquisas qualitativas publicadas em periódicos de enfermagem, evidenciou pesquisas voltadas para temáticas como formação em enfermagem, áreas de atuação, base/fundamentos/concepções de cuidado de enfermagem e assuntos profissionais, e envolve majoritariamente a metodologia qualitativa ${ }^{5-8}$.
Os métodos qualitativos têm trazido resultados significativos tanto para o desenvolvimento da enfermagem enquanto profissão, quanto para a promoção de uma ciência e de uma prática que contemplam a humanização no cerne de seu desenvolvimento.

Além disso pode-se afirmar que implementações de processos de trabalho da enfermeira obstétrica no parto e nascimento oriundos de resultados de pesquisas qualitativas, têm demonstrado e promovido mais segurança e melhor assistência para as mulheres em contexto gestacional e contribuído para a qualificação das profissionais da área.

\section{Referências}

1. Ray MA. A philosophical method to study nursing. In: Leininger MM. Qualitative research methods in nursing. New York: Grune \& Stratton; 1985.

2. Boemer MR, Rocha SMM. A pesquisa em enfermagem: notas de ordem histórica e metodológica. Saúde e Sociedade. 1996;5(2):77-88.

3. Saver JL. Using a phenomenological research method to study nursing phenomena. In: Leininger MM. Qualitative research methods in nursing. New York: Grune \& Stratton; 1985.

4. Merleau-Ponty M. Ciências do homem e fenomenologia. São Paulo: Saraiva; 1973.

5. Lacerda MR, Labronici LM. Papel social e paradigmas da pesquisa qualitativa de enfermagem. Rev Bras Enferm. 2011 ;64(2):359-364. doi: 10.1590/S003471672011000200022

6. Teles JM, Bonilha ALL. Observação em coleta de dados na área de enfermagem obstétrica: um relato de experiência. Rev Enferm UFSM. 2012;2(1):198-204.

7. Wolf LA. What Qualitative Research Can Do for You: Deriving Solutions and Interventions from Qualitative Findings. J Emerg Nurs. 2017;43(5):484-485. doi: 10.1016/i. jen.2016.06.001

8. Arieli D, Tamir B, Man M. Teaching qualitative research as a means of socialization to nursing. Nurse Educ Today. 2015;35(6):795-9. doi: 10.1016/i.nedt.2015.02.021 